\title{
The craftsman's toolbox: Stents, coils, glue, and sometimes a scalpel
}

\author{
Grant Fankhauser, MD, ${ }^{\mathrm{a}}$ and Abe DeAnda, Jr, $\mathrm{MD}^{\mathrm{b}}$
}

\author{
From the Divisions of ${ }^{\mathrm{a}}$ Vascular Surgery and ${ }^{\mathrm{b}}$ Cardiovascular Surgery, University of Texas Medical Branch-Gal- \\ veston, Galveston, Tex. \\ Disclosures: Authors have nothing to disclose with regard to commercial support. \\ Received for publication March 7, 2018; accepted for publication March 9, 2018; available ahead of print April 3 , \\ 2018. \\ Address for reprints: Abe DeAnda, Jr, MD, Division of Cardiothoracic Surgery, UTMB-Galveston, 301 Univer- \\ sity Blvd, Galveston, TX 77551 (E-mail: abdeanda@utmb.edu). \\ J Thorac Cardiovasc Surg 2018;156:e119-20 \\ $0022-5223 / \$ 36.00$ \\ Copyright (c) 2018 by The American Association for Thoracic Surgery \\ https://doi.org/10.1016/j.jtcvs.2018.03.027
}

Aneurysms of the bronchial arteries (BAAs) are exceptionally rare and often idiopathic. Intrapulmonary BAAs may present with hemoptysis, whereas extrapulmonary mediastinal BAAs may present with life-threatening hemorrhage. In their article in this issue of the Journal, San Norberto and colleagues ${ }^{1}$ present a case of one such aneurysm diagnosed by computed tomography in a patient presenting with chest pain. The aneurysm was treated with endovascular techniques that used a combination of coil and glue embolization. The treatment was successful, with no recurrence on 12-month follow-up.

So few cases of BAA have been described that there is no consensus regarding optimal diagnostic approaches or treatment. Because presenting symptoms can be nonspecific, the diagnosis will almost always be made incidentally during chest imaging. There does not appear to be an association between aneurysm size and the risk of rupture, similar to aneurysms of the smaller visceral arteries. ${ }^{2}$ Once a BAA has been diagnosed, treatment is recommended, because there is little experience to support observation of these aneurysms. The caveat, of course, is that there is equally a paucity of information regarding risk of rupture, because longitudinal temporal data are lacking. This finding thus potentially represents an acute diagnosis of a chronic disease.

Various treatment methods have been described for BAA, including open surgery, video-assisted thoracoscopic surgery, and endovascular techniques. San Norberto and colleagues ${ }^{1}$ describe their use of endovascular coiling and gluing. These techniques have proved successful in previous case reports. ${ }^{3,4}$ There have been no reports of bronchial or pulmonary ischemia after embolization, but care should be taken to prevent embolization of glue or particles into the efferent aneurysms vessels, which might lead directly to tissue necrosis.

The bronchial arteries are small, and the aneurysms may be near the ostium, making successful embolization

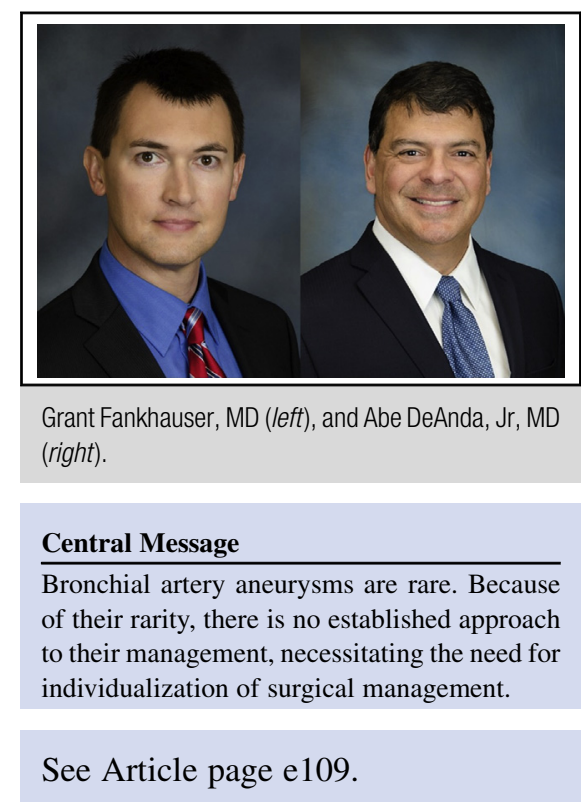

difficult without risking migration of the embolization material distally in the thoracic aorta. In these cases, a thoracic stent graft can be deployed across the ostium of the bronchial artery. Such techniques will reduce pressure in the aneurysm, but they may not lead to aneurysm thrombosis or stop flow completely. Some of these aneurysms may be secondary to an infectious process. It is generally believed that covered stents may serve as a nidus for persistent infection to a greater degree than bare metal stents or coils. There have been no reports of stent graft infection after treatment of bronchial artery aneurysms, but if an infectious etiology is high on the differential diagnosis list, it may be safer to avoid implantation of a stent graft.

For aneurysms not amenable to endovascular treatment, video-assisted thoracoscopic surgery and mediastinoscopy offer an option for less invasive surgical treatment. Once identified, the affected bronchial arteries can be clipped or cauterized for definitive control. Follow-up imaging may be less necessary for surgically treated aneurysms than for those treated with endovascular techniques. Given the unclear etiology of these aneurysms, however, surveillance for de novo aneurysms may still be warranted. Surgical exploration also offers the ability to drain the area if an infection is suspected. For a suspected inflammatory etiology, however, the lessons learned from inflammatory abdominal aortic aneurysms ${ }^{5}$ could be applied to favor an 
endovascular approach, rather than entering a hostile surgical field and possibly causing damage to surrounding structures.

Open surgical treatment should always be an option for these aneurysms, especially those presenting with lifethreatening hemorrhage. Mediastinal aneurysms may be more readily identified than intrapulmonary ones. In rare cases, lobectomy or even pneumonectomy may be required for bleeding aneurysms that cannot be further localized. For this rare entity, with an unknown natural history but with significant risk if rupture occurs, every tool in the toolbox must be available.

\section{References}

1. San Norberto EM, García JU, Montes JM, Vaquero C. Endovascular treatment of bronchial aneurysms. J Thorac Cardiovasc Surg. 2018;156: e109-17.

2. Fankhauser GT, Stone WM, Naidu SG, Oderich GS, Ricotta JJ, Bjarnason H, et al The minimally invasive management of visceral artery aneurysms and pseudoaneurysms. J Vasc Surg. 2011;53:966-70.

3. Lü PH, Wang LF, Su YS, Lee DH, Wang SX, Sun L, et al. Endovascular therapy of bronchial artery aneurysm: five cases with six aneurysms. Cardiovasc Intervent Radiol. 2011;34:508-12.

4. Izaaryene J, Vidal V, Bartoli JM, Gaubert JY. Multiple bronchial artery aneurysms: successful treatment with ethylene-vinyl alcohol copolymer (Onyx $\left.{ }^{\circledR}\right)$. Diagn Interv Imaging. 2016;97:125-7.

5. Stone WM, Fankhauser GT, Bower TC, Oderich GS, Oldenburg WA, Kalra M, et al. Comparison of open and endovascular repair of inflammatory aortic aneurysms. J Vasc Surg. 2012;56:951-5; discussion 955-6. 